Edith Cowan University

Research Online

Research outputs 2012

$1-1-2012$

\title{
Early diet quality in a longitudinal study of Australian children: associations with nutrition and body mass index later in childhood and adolescence
}

\author{
Claire Meyerkort \\ Wendy H. Oddy \\ Therese O'Sullivan \\ Edith Cowan University \\ J Henderson \\ Craig Pennell
}

Follow this and additional works at: https://ro.ecu.edu.au/ecuworks2012

Part of the Medicine and Health Sciences Commons

10.1017/S2040174411000717

This is an Author's Accepted Manuscript of: Meyerkort, C., Oddy, W., O'Sullivan, T. , Henderson , J., \& Pennell , C. (2012). Early diet quality in a longitudinal study of Australian children: associations with nutrition and body mass index later in childhood and adolescence. Journal of Developmental Origins of Health and Disease, 3(1), 21-31. Available here

This article has been published in a revised form in Journal of Developmental Origins of Health and Disease. This version is free to view and download for private research and study only. Not for re-distribution, re-sale or use in derivative works. (c) Journal of Developmental Origins of Health and Disease This Journal Article is posted at Research Online.

https://ro.ecu.edu.au/ecuworks2012/307 


\title{
Early diet quality in a longitudinal study of Australian children: associations with nutrition and body mass index later in childhood and adolescence
}

\author{
C. E. Meyerkort ${ }^{1}$, W. H. Oddy ${ }^{2}$, T. A. O'Sullivan ${ }^{2}$, J. Henderson ${ }^{1}$ and C. E. Pennell ${ }^{1 *}$ \\ ${ }^{1}$ School of Women's and Infants' Health, The University of Western Australia, Perth, Australia \\ ${ }^{2}$ Telethon Institute for Child Health Research, Centre for Child Health Research, The University of Western Australia, Perth, Australia
}

\begin{abstract}
Obesity has origins extending to antenatal and early postnatal periods; however, the relationship between early postnatal diet and subsequent obesity is not well defined. The aims of this study were to determine whether early childhood dietary quality was associated with (a) infant and adolescent nutrition and (b) body mass index (BMI) in childhood and adolescence. The degree to which early nutrition and growth factors determine BMI throughout childhood and adolescence was also explored. This research was conducted using the Raine Study, a longitudinal survey of Australian children assessed from mid-gestation to 17 years of age. A dietary quality index, the Raine Eating Assessment in Toddler score, was assigned to 2562 participants to assess early nutrition. Linear regression determined that breastfeeding was associated with dietary quality at 1-3 years. Dietary elements at 14 years of age were related to earlier dietary quality. There were no consistent associations between early diet and BMI at 3, 5, 8, 10, 14 or 17 years. In contrast, birth weight and infant weight gain were significantly associated with BMI at these ages. This study suggests that early dietary patterns are associated with aspects of diet in adolescence, likely reflecting the influence of maternal reporting. Birth weight and early growth appear to be more important determinants of adolescent BMI than early diet and nutrition. While optimizing early diet by maternal nutritional education has potential to influence later nutrition, interventions focussing on early weight gain may have a greater impact on the obesity epidemic.
\end{abstract}

Received 21 December 2010; Revised 12 April 2011; Accepted 31 October 2011; First published online 5 December 2011

Key words: children, diet quality, obesity, Raine Study

\section{Introduction}

Obesity is a significant global health problem, with overweight individuals now seen across populations of children and adults from developed and developing nations. ${ }^{1}$ Worldwide, obesity is among the five leading risks for mortality ${ }^{2}$ and in several developed populations it has recently become the greatest cause of disease or death. ${ }^{3,4}$ Over $25 \%$ of children are estimated to be overweight or obese in developed regions ${ }^{5}$ and the prevalence of paediatric obesity is increasing. 1,5

Excess weight in childhood is associated with a multitude of short-, medium- and long-term consequences, which have physical, psychological and financial effects. ${ }^{1}$ Clearly, reducing the burden of obesity is a public health priority; however, reviewing the treatment of childhood obesity has failed to illustrate the most effective interventions to combat this problem. ${ }^{6}$ This highlights the need to better understand the factors that influence obesity development.

There is evidence that dietary patterns and behaviour related to weight gain are established early in life and may persist with age. $^{7-10}$ There is also growing knowledge that several dis-

\footnotetext{
*Address for correspondence: Dr C. E. Pennell, School of Women's and Infants' Health, M550, The University of Western Australia, 2nd Floor A Block, King Edward Memorial Hospital, Subiaco 6008, Perth, Australia. (Email: craig.pennell@uwa.edu.au)
}

eases including obesity, which manifest later in life, have origins stemming back to early periods of development. ${ }^{1-14}$ Both of these concepts represent important windows of opportunity for early obesity prevention.

Initial research into the developmental origins of health and disease focussed on how antenatal factors such as birth weight influence health and disease later in life. More recently, it has been acknowledged that the phase during which development may be altered is not limited to gestation; rather it extends from the peri-conception period through to the postnatal period. ${ }^{15}$ Despite this recognition, the contribution of the early postnatal environment to the developmental origins of obesity, in particular the role of nutrition, is incompletely understood. ${ }^{15}$ One aspect that appears to be important is rapid weight gain in early life. ${ }^{16,17}$ As weight gain is influenced by current diet, nutrition and energy intake, a greater understanding of the relationship between early postnatal nutrition and weight is required.

A small reduction in the risk of obesity later in life has been observed in breastfed infants compared to formula-fed infants, ${ }^{18}$ although there is no consistent evidence that breastfeeding causally reduces obesity risk. ${ }^{19}$ Specific macronutrients have also been examined in relation to subsequent overweight or obesity; ${ }^{20,21}$ however, human diets are comprised of a variety of foods and drinks, therefore there are restrictions associated with examining the diet from the point of view of a single element. ${ }^{22}$ 
The relationship between overall dietary quality in early life and weight later in life is not adequately described in the literature. A handful of studies have explored these links in children, ${ }^{23-26}$ although the cross-sectional study design in the majority of previous work has been a limitation and provided inconsistent results.

The Western Australian Pregnancy Cohort (Raine) Study is a longitudinal study that has collected dietary and nutrition information from birth to 3 years of age and in adolescence. Comprehensive anthropometric and sociodemographic data have also been gathered from birth up to the age of 17 years. Therefore, it provides opportunities to explore whether early diet influences nutrition and growth later in life. In this study, we investigated whether maternally reported early childhood dietary quality was associated with (a) infant and adolescent nutrition and (b) body mass index (BMI) throughout childhood and adolescence. The degree that early nutrition and growth factors account for BMI in childhood and adolescence was also explored within the Raine cohort.

\section{Methods}

\section{Study population}

Participants were enrolled in the Western Australian Pregnancy Cohort (Raine) Study, a population-based prospective cohort study in Perth, Western Australia, between May 1989 and November 1991. Initially, 2900 pregnant women were recruited between 16 and 20 weeks' gestation into a randomized controlled trial to evaluate the effects of repeated ultrasound in pregnancy. Recruitment occurred predominantly at public antenatal clinics at King Edward Memorial Hospital (KEMH), the only tertiary obstetric hospital in Western Australia. Full details of the study are documented elsewhere. ${ }^{27-29}$ The cohort has been demonstrated to be representative of the population presenting to the antenatal tertiary referral centre in Western Australia. ${ }^{30}$ The ethics committees of KEMH and Princess Margaret Hospital granted approval for the study protocols. The primary caregiver, who was the mother in most cases, provided written and informed consent. The parents of 2868 live-born children consented for follow-up at the ages of $1,2,3,5,8,10,14$ and 17 years.

\section{Nutrition and dietary data}

Nutrition in the first year of life was ascertained from questionnaires administered by study nurses at the 1-3-year follow-up visits. At each visit the primary caregiver was asked whether the child was breastfed; when breastfeeding was stopped; when solid foods were first given; and when other types of milk were introduced. All measures were recorded in months. The duration of exclusive breastfeeding was determined from this information.

At the 1-3-year follow-up assessments the primary caregiver also completed a 24-h dietary recall of their child's diet. This requested a description of the type and quantity of all food and drink consumed for breakfast, lunch, dinner and snacks in 1 day. Accurate quantitative data were not consistently recorded by the caregiver, therefore each time a food or drink was written on the dietary recall, this was considered one 'eating occasion' for that particular item. In order to utilize the semi-quantitative dietary data from the Raine cohort, we developed a new index, the Raine Eating Assessment in Toddlers (EAT) score, to provide a measure of overall dietary quality at these ages. This was based on a previously published paediatric dietary index, ${ }^{24}$ although it was modified for use with the Raine cohort data. The EAT score was constructed around seven component food groups where there exists evidence of their nutritional benefit or detriment in young children: (1) whole grains, (2) vegetables, (3) fruit, (4) a meat ratio, (5) dairy, (6) snack foods, (7) soda and drinks. Breast milk and breast milk substitutes were not included in the EAT score at any time.

Individuals were assigned a score out of 10 for each component. Components one to five were defined as 'healthy' for their nutritional benefits ${ }^{31}$ and greater frequency of consumption of foods from these components resulted in scores closer to 10. Components six and seven were defined as 'unhealthy' as they are not recommended for young children ${ }^{31}$ and greater frequency of consumption of these resulted in scores closer to zero. The overall score for an individual was determined by the sum of the seven component scores, such that the possible total score ranged from 0 to 70 . Individuals with the highest scores were those whose $24-\mathrm{h}$ recalls recorded more healthy foods relative to less unhealthy foods. Therefore, this research defines better dietary quality over the ages of 1-3 years by higher scores and poorer dietary quality by lower scores.

Diet and nutrition were assessed at the 14-year follow-up by a semi-quantitative food frequency questionnaire (FFQ) developed by the Commonwealth Scientific and Industrial Research Organisation (CSIRO) ${ }^{32}$ The FFQ listed 212 individual foods, mixed dishes and beverages. The frequency of consumption in the preceding 12 months, in relation to standard serving sizes, was estimated. The FFQ was intended for the primary caregiver to complete with the study adolescent, as adolescents and children may be less likely to recall diet well. ${ }^{33} \mathrm{~A}$ research nurse clarified missing responses with the study participant, the FFQ data were entered twice and CSIRO confirmed the data. Additional details of the FFQ and a description of those who completed it are published elsewhere. ${ }^{34,35}$

From the FFQ information, two major dietary patterns, healthy and Western, were identified through factor analyses in previous research. ${ }^{34}$ All participants received a score for both dietary patterns. Foods loading on the healthy dietary pattern included wholegrain cereals, fresh fruit, legumes, steamed, grilled or canned fish and vegetables, excluding potatoes. ${ }^{34}$ Foods loading on the Western dietary pattern included take-away foods, red meat, processed meat, full-fat dairy foods, fried potatoes, refined cereals, cakes, confectionary and soft drinks. ${ }^{34}$ Estimates of 40 macro- and micronutrients were also calculated, based on usual intakes of the 212 foods listed in the FFQ. The present research utilizes 
the total grams of carbohydrates, protein, fat, fibre and sugar consumed per day.

\section{Anthropometric assessment}

Physical examinations at birth assessed birth weight and length. From these measurements ponderal index was calculated (weight at birth in kilograms divided by the length in metres cubed). Anthropometric data were obtained by physical assessments at the Telethon Institute for Child Health Research. Weight was measured to the nearest $100 \mathrm{~g}$ using a Wedderburn digital chair scale with children wearing underclothes. Height was measured to the nearest $0.1 \mathrm{~cm}$ with a Holtain stadiometer. BMI was calculated as weight in kilograms divided by the height in meters squared. This study uses BMI at 3, 5, 8, 10, 14 and 17 years of age.

\section{Covariates}

Information regarding pregnancy, infant, parental and socioeconomic characteristics was collected from questionnaires and physical examinations at $16-20$ and 34 weeks' gestation, birth, 1-3 years of age. Maternal smoking was assessed in both antenatal questionnaires. Marital status was categorized into those who were married or de facto, and those separated, divorced, widowed or never married. The level of maternal and paternal education after school-leaving was assessed. Family size was evaluated by asking how many other children were at home, in addition to the study participant.

To assess socioeconomic status, cohort members were assigned Socioeconomic Indexes for Areas (SEIFA) scores at each year of follow-up. The SEIFA consist of four indices, each measuring a slightly different aspect of socioeconomic conditions within an area. ${ }^{36}$ This research uses the Index of Relative Socioeconomic Advantage and Disadvantage (IRSAD), which measures the spectrum of socioeconomic well-being, from the most disadvantaged to the most advantaged. ${ }^{36}$ The IRSAD is based on 21 measures including income, occupation and education within a specific geographical area. Higher IRSAD scores reflect a relative lack of disadvantage and greater advantage. $^{36}$

The level of physical activity at age 14 years was determined by asking participants the duration in hours, that they exercised enough to become breathless or sweaty, out of school. To provide a measure of the timing of puberty in females, the year of the first menstrual period was used.

\section{Statistical analyses}

Analyses were based on cohort members who answered at least one 24-h recall at the 1-3-year follow-up assessments. Descriptive statistics were calculated for pregnancy, family, anthropometric and nutritional characteristics. Medians and interquartile ranges are presented for continuous variables and numbers and percentages of participants are presented for categorical variables. To evaluate gender differences, the Mann Whitney $(U)$ test was performed on continuous variables and Pearson's $\chi^{2}$-test was used for comparison of categorical variables.

To assess whether nutrition in the first year of life was correlated with dietary quality over years $1-3$, linear regression was performed. Univariate regression involved the Raine EAT score as the dependent variable, with either duration of breastfeeding, duration of exclusive breastfeeding or age of introduction of solids as the independent variable in three separate models. The multivariable linear regression adjusted for the potential confounders of maternal tertiary education, maternal age, maternal smoking, the number of other children at home, IRSAD and age of the study participant.

To determine whether the EAT score was associated with nutrition at 14 years, linear regression was carried out. The EAT score at years 1-3 were the independent variables and dietary elements (carbohydrates, protein, fat, fibre and sugar) were separate dependent variables. Maternal tertiary education, maternal age, number of other children in the home, maternal smoking, age-specific IRSAD, hours of physical activity per week at 14 years, gender and age were included in multivariate analyses to adjust for potential confounding.

Linear regression was also used to determine associations between EAT scores and BMI later in life. The EAT score at years 1-3 were each independent variables in three separate models including BMI at 3, 5, 8, 10, 14 and 17 years of age as dependent variables. BMI was positively skewed from the age of 5 years and older; therefore, BMI variables were logtransformed. Multivariate regression was adjusted for age, birth weight, maternal smoking and age-specific IRSAD. Analyses involving 14- and 17-year-old females were also adjusted for the year of first menstruation.

Gender interactions were explored in all of the linear regression analyses described above. The interaction term in each model consisted of gender and the independent variable for that particular linear model. Significant interaction terms were retained in the regression models. To reduce the potential for a correlated error structure the following covariates were mean-centred: gestational age at birth, birth weight, ponderal index, breastfeeding duration, exclusive breastfeeding, age of introduction of solids, weight gain in the first year of life, child's BMI, IRSAD, maternal age, duration of physical activity at 14 years and fat, protein, carbohydrate, fibre and sugar intake at 14 years.

Analyses were performed using Predictive Analytics Software (PASW) Statistics 17 (SPSS 17). ${ }^{37}$ Statistical significance was considered where $P<0.05$.

\section{Results}

The primary caregiver of 2562 (89\%) cohort members answered at least one 24-h recall at the ages of 1, 2 or 3 years. Compared with non-responders, responders were more likely to be older, married, have completed tertiary education and 
Table 1. Cohort characteristics: participants who completed at least one 24-h food recall at the 1-, 2-or 3-year follow-ups of the Western Australian Pregnancy Cohort (Raine) Study $(n=2562)$

\begin{tabular}{|c|c|c|c|c|c|}
\hline & $\mathrm{Ma}$ & es $(n=1313)$ & Fem & les $(n=1249)$ & \\
\hline & Media & (IQR) or $n \%^{\mathrm{a}}$ & Media & $\mathrm{n}(\mathrm{IQR})$ or $n \%$ & $P$-value \\
\hline Pregnancy characteristics & & & & & \\
\hline Gestational age at birth (days) & 277.0 & $(268.0-284.0)$ & 277.0 & $(268.0-285.0)$ & 0.938 \\
\hline Birth weight $(\mathrm{g})$ & 3415.0 & $(3055.0-3750.0)$ & 3280.0 & $(2925.0-3600.0)$ & $<0.001$ \\
\hline Ponderal Index $\left(\mathrm{kg} / \mathrm{m}^{3}\right)$ & 27.8 & $(25.9-31.5)$ & 28.1 & $(26.1-32.1)$ & 0.035 \\
\hline Maternal smoking at 16 weeks' gestation & & & & & \\
\hline Yes & 300 & 22.8 & 324 & 25.9 & \\
\hline No & 985 & 75.0 & 894 & 71.6 & 0.060 \\
\hline Not stated & 28 & 2.2 & 31 & 2.5 & \\
\hline Parental characteristics ${ }^{\mathrm{b}}$ & & & & & \\
\hline Maternal age (years) & 28.0 & $(23.8-32.0)$ & 28.0 & $(24.0-32.0)$ & 0.878 \\
\hline Paternal age (years) & 31.0 & $(27.0-35.0)$ & 31.0 & $(28.0-36.0)$ & 0.235 \\
\hline Maternal BMI $\left(\mathrm{kg} / \mathrm{m}^{2}\right)$ & 21.4 & $(19.7-23.8)$ & 21.3 & $(19.7-23.5)$ & 0.455 \\
\hline Paternal BMI $\left(\mathrm{kg} / \mathrm{m}^{2}\right)$ & 24.2 & $(22.1-26.4)$ & 24.0 & $(22.2-26.2)$ & 0.998 \\
\hline Maternal tertiary education & 570 & 43.4 & 554 & 44.4 & 0.631 \\
\hline Paternal tertiary education & 694 & 52.9 & 632 & 50.6 & 0.253 \\
\hline Maternal marital status & & & & & \\
\hline Married/de facto & 1103 & 84.0 & 1023 & 81.9 & \\
\hline Never married, separated, divorced/widowed & 186 & 14.2 & 193 & 15.5 & 0.314 \\
\hline Not stated & 24 & 1.8 & 33 & 2.6 & \\
\hline Family characteristics $^{\mathrm{b}}$ & & & & & \\
\hline IRSAD $^{c}$ & 1027.6 & $(957.4-1087.9)$ & 1020.6 & $(952.6-1094.7)$ & 0.656 \\
\hline Number of other children at home & & & & & \\
\hline 0 & 644 & 49.0 & 589 & 47.2 & \\
\hline 1 & 390 & 29.7 & 366 & 29.3 & 0.560 \\
\hline$\geqslant 2$ & 255 & 19.4 & 261 & 20.9 & \\
\hline Not stated & 24 & 1.9 & 33 & 2.6 & \\
\hline Participant's BMI at follow-up $\left(\mathrm{kg} / \mathrm{m}^{2}\right)$ & & & & & \\
\hline Year 1 & 17.2 & $(16.4-18.2)$ & 16.7 & $(15.8-17.7)$ & $<0.001$ \\
\hline Year 2 & 16.1 & $(15.3-16.9)$ & 15.6 & $(14.8-16.5)$ & $<0.001$ \\
\hline Year 3 & 16.2 & $(15.4-17.0)$ & 15.9 & $(15.0-16.8)$ & $<0.001$ \\
\hline Year 5 & 15.6 & $(14.8-16.6)$ & 15.4 & $(14.6-16.6)$ & 0.199 \\
\hline Year 8 & 16.2 & $(15.2-17.5)$ & 16.3 & $(15.2-18.0)$ & 0.617 \\
\hline Year 10 & 17.7 & $(16.3-20.0)$ & 17.9 & $(16.3-20.5)$ & 0.456 \\
\hline Year 14 & 20.0 & $(18.3-22.8)$ & 20.6 & $(18.9-23.3)$ & 0.001 \\
\hline Year 17 & 21.8 & $(19.9-24.1)$ & 22.3 & $(20.1-24.6)$ & 0.050 \\
\hline Duration of physical activity $(\mathrm{h})^{\mathrm{d}}$ & 3.0 & $(2.0-4.0)$ & 3.0 & $(1.0-3.0)$ & $<0.001$ \\
\hline
\end{tabular}

IQR, interquartile range; IRSAD, Index of Relative Socioeconomic Advantage and Disadvantage; BMI, body mass index.

${ }^{a}$ Values are median and IQR for continuous variables and $n \%$ for categorical variables.

${ }^{\mathrm{b}}$ Parental and family characteristics ascertained from surveys at 16 and 34 weeks' gestation.

${ }^{\mathrm{c}}$ Calculated from year 1 follow-up information. Index scores ranges from 683 to 1231, higher scores reflect a relative socioeconomic advantage.

${ }^{\mathrm{d}}$ At 14 years, h/week undertaken outside of school that cause breathlessness or sweating.

higher IRSAD scores and less likely to smoke (all $P<0.001$ ). The parents who responded were also more likely to have fewer children $(P=0.002)$, completed tertiary education $(P<0.001)$ and higher IRSAD scores $(P<0.001)$. Mothers who answered the recall were more likely to have breastfed their child $(P<0.001)$ and for a longer duration $(P=0.020)$, than those mothers who did not respond to the recall.
Demographic and anthropometric data are presented in Table 1. Males and females were significantly different for birth weight, ponderal index, BMI in early childhood and adolescence and the duration of physical activity at 14 years. Median BMI increased after 7 years of age with significant differences between males and females at ages $1-3$ and 14 years (all $P$-values $\leqslant 0.001$, Table 1 ). 
Table 2. Nutrition descriptive statistics on Raine Study participants with at least one 24-h food recall in year 1-3-year follow-ups $(n=2562)$

\begin{tabular}{|c|c|c|c|}
\hline & Males $(n=1313)$ & Females $(n=1249)$ & \\
\hline & Median (IQR) & Median (IQR) & $P$-value \\
\hline \multicolumn{4}{|l|}{ Infant nutrition } \\
\hline Breastfeeding duration (months) & $7.0(3.0-12.0)$ & $7.0(3.0-12.0)$ & 0.836 \\
\hline Exclusive breastfeeding duration (months) & $3.0(1.0-4.0)$ & $3.0(1.0-4.0)$ & 0.363 \\
\hline Age solids introduced (months) & $4.0(4.0-5.0)$ & $4.0(4.0-5.0)$ & 0.093 \\
\hline \multicolumn{4}{|l|}{ Raine EAT score values ${ }^{\mathrm{a}}$} \\
\hline Year 1 & $41.7(35.0-48.3)$ & $41.7(35.0-48.3)$ & 0.521 \\
\hline Year 2 & $38.3(31.7-45.0)$ & $40.0(31.7-46.7)$ & 0.015 \\
\hline Year 3 & $36.7(30.0-43.4)$ & $38.3(30.0-45.0)$ & 0.135 \\
\hline \multicolumn{4}{|l|}{ Nutrition at 14 years } \\
\hline Total kJ & $10118.3(8511.3-12241.3)$ & $8358.6(6803.1-10461.7)$ & $<0.001$ \\
\hline Total carbohydrates (g) & $290.8(236.0-350.9)$ & $239.8(191.6-302.6)$ & $<0.001$ \\
\hline Total protein $(\mathrm{g})$ & $101.4(84.4-120.9)$ & $82.8(66.0-104.3)$ & $<0.001$ \\
\hline Total fat $(\mathrm{g})$ & $97.7(75.2-120.0)$ & $78.6(61.5-99.9)$ & $<0.001$ \\
\hline Total fibre (g) & $23.8(18.6-30.6)$ & $22.1(17.2-28.1)$ & $<0.001$ \\
\hline Total sugar (g) & $159.7(126.4-205.6)$ & $137.4(103.4-179.6)$ & $<0.001$ \\
\hline Healthy dietary pattern ${ }^{\mathrm{b}}$ & $-0.11(-0.69-0.50)$ & $-0.09(-0.06-0.55])$ & 0.095 \\
\hline Western dietary pattern ${ }^{\mathrm{b}}$ & $0.04(-0.46-0.65)$ & $-0.34(-0.78-0.32)$ & $<0.001$ \\
\hline
\end{tabular}

IQR, interquartile range; EAT, Eating Assessment in Toddlers.

${ }^{a}$ Range is from 0 to 70 , higher scores reflect better dietary quality.

${ }^{\mathrm{b}}$ Healthy and Western are dietary patterns identified through factor analysis. Range for healthy: -2.12 to 5.01. Range for Western: -2.07 to 4.74 .

Descriptive statistics for measures of nutrition are outlined in Table 2. There were no gender differences in nutrition in the first year of life, measured by the duration of breastfeeding and age that solid foods were introduced. Females had higher year 2 and year 3 EAT scores, although the difference was only statistically significant at the age of 2 years. The Raine EAT scores declined over 1-3-year follow-ups, driven by an increase in the frequency of consumption of unhealthy snack foods and soft drinks, and a decrease in the frequency of consumption of food groups such as dairy, whole grains and vegetables. Considering nutrition at 14 years, males had a higher daily intake of kilojoules, carbohydrates, protein, fat, fibre and sugar (all $P<0.001$ ). Males also had significantly higher Western dietary pattern scores $(P<0.001)$.

\section{Infant nutrition and early dietary quality}

All three measures of nutrition during the period from birth to 1 year of age were associated with the EAT scores at 1-3 years of age (Table 3). Concordant results were obtained for males and females and therefore the EAT score was assessed in a combined male and female model. The breastfeeding measures remained significant in adjusted analyses, although the magnitude of the association for breastfeeding and exclusive breastfeeding with the score were reduced by between 1.7-2.2 and $1.3-1.8$, respectively. The age that solid foods were introduced became non-significant in adjusted analyses.

\section{Early dietary quality and adolescent diet}

Higher Raine EAT scores were associated with greater fibre intake at 14 years at all 3 years of follow-up $(P<0.001)$. This association remained significant after adjusting for several potential confounding factors (Table 4). Higher EAT scores at years 1 and 2 were inversely associated with fat intake at 14 years, but after adjustment this relationship became nonsignificant. Higher Raine EAT scores at year 3 were associated with higher protein intake before and after adjusting for potential confounders. The models involving fibre and sugar as dependent variables demonstrated discordant results for males and females at year 2. The interaction term involving the EAT score at year 2 and gender was significant for sugar $(P=0.045)$ and fibre intakes $(P=0.031)$.

\section{Early nutrition and growth and later BMI}

There were no consistent associations between the EAT scores at years 1-3 and BMI throughout childhood and adolescence in the unadjusted and adjusted analyses (Table 5). The EAT score at year 1 was associated with BMI at age 5, 8, 10, 14 and 17 years, although this association become non-significant at the age of 14 and 17 years after adjusting for several confounding factors. Analyses involving males and females separately yielded concordant results; therefore, a combined male and female model is presented. 


\section{Discussion}

This study suggests that maternally reported early nutrition and dietary quality is associated with elements of diet during adolescence. In contrast to the associations between early and late dietary patterns, late childhood and adolescent BMI were not associated with early dietary quality. Antenatal and postnatal factors such as birth weight and growth in the first year of life as well as maternal socioeconomic factors appear to play a more important role in determining BMI.

\section{Associations between infant nutrition and early childhood diet}

Optimal infant nutrition is achieved by exclusive breastfeeding for the first 6 months of life, followed by breastfeeding with complementary foods for up to 2 years. ${ }^{38}$ In this research, a longer duration of exclusive or non-exclusive breastfeeding, considered to provide more optimal nutrition, was independently associated with better dietary quality over 1-3 years of age. Exclusive breastfeeding had approximately double the magnitude of association on dietary quality, compared to nonexclusive breastfeeding.

These findings are consistent with those of a cross-sectional survey of 2-6-year-old children, ${ }^{39}$ although that study examined fruit and vegetable intake, rather than overall dietary quality. Children who had been breastfed ate more fruit than those who were not breastfed. ${ }^{39}$ Similarly, a comparison of breastfed with formula-fed infants revealed that the highest percentage of consumers of healthier foods, such as fruits and vegetables, were the breastfed infants. ${ }^{40}$ It is likely that associations between breastfeeding and dietary quality may be due to residual socioeconomic confounding and strongly influenced by maternal reporting. There is also evidence supporting plausible biological mechanisms, through which breastfeeding may programme healthier dietary habits later in life. ${ }^{41}$ Given that infant feeding and dietary quality in early childhood both reflect maternal choices, this highlights the paramount role a child's mother can play in influencing nutrition across the early years of life.

\section{The relationship of childhood dietary quality to adolescent dietary patterns}

Maternal reporting of dietary quality in early childhood was associated with elements of diet at the age of 14 years. Higher EAT scores were given to toddlers consuming greater frequency of wholegrain foods, which are a valuable source of fibre. ${ }^{31}$ In this study, greater maternal reporting of wholegrain consumption in early life was linked to increased fibre consumption as reported by the mother and study participant in adolescence. Higher EAT score values were also assigned to children in this study who consumed fewer sweet and savoury snack foods, many of which are high in fat. ${ }^{31}$ The association between higher EAT scores and lower fat consumption at 14 years suggests that 
Table 4. Associations between the Raine EAT score in early childhood and diet at 14 years of age

\begin{tabular}{|c|c|c|c|c|c|}
\hline & Carbohydrates $^{\mathrm{a}}$ & Protein $^{a}$ & $\mathrm{Fat}^{\mathrm{a}}$ & Fibre $^{\mathrm{a}}$ & Sugar $^{\mathrm{a}}$ \\
\hline \multicolumn{6}{|c|}{ Raine EAT score at year $1(n=2244)$} \\
\hline \multicolumn{6}{|c|}{ Unadjusted } \\
\hline$\beta$ (s.e.) & $-0.178(0.259)$ & $-0.044(0.085)$ & $-0.268(0.094)$ & $0.101(0.025)$ & $-0.057(0.176)$ \\
\hline$P$-value & 0.493 & 0.608 & 0.004 & $<0.001$ & 0.747 \\
\hline \multicolumn{6}{|l|}{ Adjusted $^{\mathrm{b}}$} \\
\hline$\beta$ (s.e.) & $-0.162(0.297)$ & $-0.066(0.096)$ & $-0.195(0.106)$ & $0.092(0.029)$ & $-0.106(0.205)$ \\
\hline$P$-value & 0.585 & 0.493 & 0.066 & 0.002 & 0.604 \\
\hline \multicolumn{6}{|c|}{ Raine EAT score at year $2(n=1903)$} \\
\hline \multicolumn{6}{|c|}{ Unadjusted } \\
\hline$\beta$ (s.E.) & $-0.270(0.259)$ & $0.028(0.085)$ & $-0.276(0.094)$ & $0.123(0.025)$ & $-0.050(0.176)$ \\
\hline$P$-value & 0.298 & 0.739 & 0.003 & $<0.001$ & 0.778 \\
\hline \multicolumn{6}{|l|}{ Adjusted $^{\mathrm{b}}$} \\
\hline$\beta$ (s.E.) & $0.401(0.389)$ & $0.0 .174(0.126)$ & $-0.177(0.139)$ & $0.187(0.038)$ & $0.412(0.267)$ \\
\hline$P$-value & 0.302 & 0.166 & 0.400 & $<0.001$ & 0.123 \\
\hline \multicolumn{6}{|c|}{ Raine EAT score at year $3(n=2044)$} \\
\hline \multicolumn{6}{|l|}{ Unadjusted } \\
\hline$\beta$ (s.E.) & $0.248(0.251)$ & $0.215(0.083)$ & $-0.139(0.093)$ & $0.167(0.024)$ & $0.291(0.169)$ \\
\hline$P$-value & 0.325 & 0.010 & 0.136 & $<0.001$ & 0.085 \\
\hline \multicolumn{6}{|l|}{ Adjusted $^{\mathrm{b}}$} \\
\hline$\beta$ (s.E.) & $0.774(0.287)$ & $0.309(0.093)$ & $0.053(0.104)$ & $0.172(0.028)$ & $0.633(0.197)$ \\
\hline$P$-value & 0.007 & 0.001 & 0.609 & $<0.001$ & 0.001 \\
\hline
\end{tabular}

EAT, Eating Assessment in Toddler.

${ }^{a}$ Carbohydrates, protein, fat, fibre and sugar were measured in grams.

${ }^{\mathrm{b}}$ Adjusted for: maternal tertiary education, maternal age, family size (number of other children in the home), maternal smoking, 14-year Index of Relative Socioeconomic Advantage and Disadvantage (IRSAD), hours of physical activity per week at 14 years, gender, age and the interaction between EAT score at year 2 and gender. The following variables were mean centred: maternal age, 14-year IRSAD and hours of physical activity per week.

maternally reported fat intake patterns are similar in childhood and in adolescence.

This study did not intend to analyse true dietary tracking, due to the different dietary data collection methods and different measures of dietary quality applied in early and late childhood. Nevertheless, the associations between maternally reported infant nutrition, early childhood dietary quality and adolescent's diet are broadly in line with consistent reporting of fibre and fat intake described previously in children. ${ }^{42,43}$

\section{Early dietary quality and BMI}

Inconsistent associations were demonstrated between early childhood dietary quality and BMI from 3 to 17 years of age. After adjusting for confounding factors, associations remained between the EAT score at year 1 and BMI at the ages of 5, 8 and 10 only. Given the lack of consistent association between the EAT scores taken at other years and BMI, it is possible that the associations observed at year 1 may be due to residual sociodemographic confounding.

To date, four studies have applied a dietary quality score to paediatric populations and measured associations with anthropometric outcomes. $^{23-26}$ Three of these have asserted links between dietary quality and measures of body mass or obesity. The first observed a weak inverse relationship between dietary quality and BMI in 9-14-year-olds. ${ }^{24}$ The second demonstrated decreasing obesity prevalence in 2-5-year-olds, when the lowest and highest dietary quality scores were compared. ${ }^{26}$ The third study found that in 11-16-year-olds, there were no significant associations between BMI and dietary quality score, although higher body fat and abdominal fat were significantly associated with lower dietary quality scores. ${ }^{25}$ These studies were all cross-sectional and therefore had limited capacity to detect whether dietary quality predicts later BMI. One longitudinal study found that dietary quality in 6-9-year-olds was not related to BMI after 2-3 years. ${ }^{23}$ These findings were consistent with our results, although our study involved a larger, younger population and diet-BMI relationships were assessed for a longer period.

The small number of paediatric studies and inconsistent associations indicate that the evidence in this area is still developing. Recent research in adult women revealed that participants with lower dietary quality were more likely to be overweight or obese after 16 years of age. ${ }^{44}$ There are important implications for obesity prevention associated with this finding. Further longitudinal investigations in young 
Table 5. Associations between the Raine EAT score in early childhood and BMI in later childhood and adolescence

\begin{tabular}{|c|c|c|c|c|c|c|}
\hline & \multicolumn{6}{|c|}{ BMI } \\
\hline & Age $3^{b}$ & Age 5 & Age 8 & Age 10 & Age 14 & Age 17 \\
\hline \multicolumn{7}{|c|}{ Raine EAT score at year $1(n=2244)$} \\
\hline \multicolumn{7}{|l|}{ Unadjusted } \\
\hline$\beta$ (s.E.) & $-0.000074(0.000216)$ & $-0.000657(0.000253)$ & $-0.000971(0.000332)$ & $-0.001389(0.000420)$ & $-0.001528(0.000476)$ & $-0.002105(0.000519)$ \\
\hline$P$-value & 0.733 & 0.009 & 0.003 & 0.001 & 0.001 & $<0.001$ \\
\hline \multicolumn{7}{|l|}{ Adjusted $^{\mathrm{a}}$} \\
\hline$\beta$ (s.E.) & $-0.000127(0.000228)$ & $-0.000620(0.000276)$ & $-0.000854(0.000365)$ & $-0.001132(0.000453)$ & $-0.001208(0.000689)$ & $-0.000967(0.000813)$ \\
\hline$P$-value & 0.578 & 0.025 & 0.019 & 0.013 & 0.080 & 0.235 \\
\hline \multicolumn{7}{|c|}{ Raine EAT score at year $2(n=1903)$} \\
\hline \multicolumn{7}{|l|}{ Unadjusted } \\
\hline$\beta$ (s.Е.) & $0.000079(0.000223)$ & $-0.000189(0.000262)$ & $-0.000026(0.000337)$ & $-0.000230(0.000421)$ & $-0.000327(0.000480)$ & $-0.001162(0.000515)$ \\
\hline$P$-value & 0.723 & 0.471 & 0.939 & 0.585 & 0.496 & 0.024 \\
\hline \multicolumn{7}{|l|}{ Adjusted $^{\mathrm{a}}$} \\
\hline$\beta$ (s.Е.) & $-0.000073(0.000231)$ & $-0.000264(0.000279)$ & $-0.000060(0.000369)$ & $-0.000065(0.00045)$ & $-0.000061(0.000711)$ & $-0.000760(0.000814)$ \\
\hline$P$-value & 0.751 & 0.344 & 0.871 & 0.886 & 0.932 & 0.351 \\
\hline \multicolumn{7}{|c|}{ Raine EAT score at year $3(n=2044)$} \\
\hline \multicolumn{7}{|l|}{ Unadjusted } \\
\hline$\beta$ (s.Е.) & $0.000046(0.000213)$ & $-0.000213(0.000249)$ & $-0.000369(0.000333)$ & $-0.000668(0.000414)$ & $-0.000518(0.000470)$ & $-0.000095(0.000512)$ \\
\hline$P$-value & 0.828 & 0.391 & 0.267 & 0.108 & 0.271 & 0.853 \\
\hline \multicolumn{7}{|l|}{ Adjusted $^{\mathrm{a}}$} \\
\hline$\beta$ (s.Е.) & $0.000153(0.000222)$ & $-0.000321(0.000271)$ & $-0.000279(0.000364)$ & $-0.000487(0.000449)$ & $-0.000587(0.000686)$ & $-0.000433(0.000771)$ \\
\hline$P$-value & 0.492 & 0.236 & 0.443 & 0.278 & 0.392 & 0.575 \\
\hline
\end{tabular}

EAT, Eating Assessment in Toddler; BMI, body mass index.

${ }^{\text {a }}$ Years 3, 5, 8 and 10 models were adjusted for birth weight, maternal smoking, socioeconomic status (age-specific Index of Relative Socioeconomic Advantage and Disadvantage (IRSAD)) and age. Years 14 and 17 models were also adjusted for puberty (year of the first menstruation in females).

${ }^{\mathrm{b}} \mathrm{BMI}$ is log-transformed at every year.

The following variables were mean centred in analyses: birth weight and IRSAD. 
children are essential before definite conclusions can be drawn, regarding the association between early dietary quality on weight later in life.

\section{Early nutrition and growth: the relationship to BMI}

Our assessment of dietary quality was not associated with BMI, although research illustrates that other measures of early nutrition and growth are important in obesity development. ${ }^{16,17,45}$ Birth weight and infant weight gain are often considered surrogate measures of foetal nutrition and early postnatal nutrition, respectively. Evidence from the Raine cohort ${ }^{46}$ and other longitudinal studies ${ }^{45}$ suggests that birth weight and BMI are positively related. Studies have also consistently demonstrated links between high infant weight gain and increased obesity risk later in life. ${ }^{47}$ Within the Raine cohort, high postnatal weight gain influenced adolescent cardiovascular risk factors, including higher BMI. ${ }^{48}$

Consistent with previous findings, we found that birth weight and weight gain over the first year of life were positively and significantly related to later BMI within the Raine cohort. In comparison, no other postnatal measure of nutrition that we assessed in infancy (breastfeeding duration or age of introduction of solids), early childhood (dietary quality measured by the Raine EAT score) or later childhood (healthy or Western dietary patterns) demonstrated significant associations with BMI.

Evidence suggests that breastfeeding has a small protective effect on the prevalence of obesity. ${ }^{18}$ When breastfeeding in the Raine cohort has been explored in relation to BMI, weight gain or risk of overweight, the results have been inconsistent. Considering duration of breastfeeding as a continuous variable yielded no associations with childhood BMI in adjusted analyses. ${ }^{46,49}$ When breastfeeding duration was analysed as a categorical ${ }^{50}$ or binary ${ }^{48}$ variable, significant associations with BMI or weight gain were observed in the cohort. Therefore, it is not unexpected that breastfeeding duration considered continuously in this research was not significantly associated with BMI in later childhood or adolescence.

\section{Strengths and limitations}

Previous studies in this area have been cross-sectional or limited by shorter durations of follow-up. A major strength of this research is that the Raine Study is longitudinal and involved a relatively large sample of children. The dietary and anthropometric data collected from birth to late adolescence meant that we could explore long-term diet-obesity relationships. The comprehensive family, environmental and sociodemographic data accumulated over the years also allowed for the consideration of potential confounders in this relationship.

There are limitations with the methodology utilized in this research. Dietary recalls based on a period of $24 \mathrm{~h}$ may not be fully representative of usual diet. Further, the original dietary data were semi-quantitative. This meant that the EAT score was limited in its capacity to depict dietary elements such as total kilojoules or total fat intake per day. This may have restricted the ability of the score to predict obesity development. It may be considered ideal to use a previously validated instrument. The semi-quantitative nature of the Raine data precluded the utiliation of indices published to date, ${ }^{24,51-53}$ as these were developed for more precise quantitative data. For this study, it was therefore necessary to develop an index specifically for the nutritional data available. The exclusion of breastfeeding data from the EAT score may be considered a limitation of this instrument. However, this allowed the inclusion of these important data as an effect modifier of the association between early childhood diet and adolescent BMI. Although a concerted attempt was made to adjust for socioeconomic status, residual confounding was likely to play a role in accounting for the associations observed between early and later dietary habits. Specifically, dietary data were based on maternal reporting in infancy, childhood and adolescence. It would have been ideal for independent assessment of the duration of breastfeeding, early dietary quality and adolescent nutrition to occur; however, this was not possible. Future studies investigating nutritional patterns across the life course should consider this issue in the study design and methodology. Care must also be taken when extrapolating these findings to the general population. The members of the cohort not included in this study, due to their lack of dietary data, were less socioeconomically advantaged, compared to the individuals included in analyses. A final potential limitation is that the cohort was recruited 20 years ago. Adult BMI in Australia has increased over the past 20-30 years. ${ }^{54}$ If this study was repeated today it is possible that the findings may differ, because higher maternal weight may create a different nutritional environment for the foetus. ${ }^{55}$

\section{Conclusion}

Early diet and nutrition have been implicated in weight status later in life. In this study, we found that maternally reported dietary patterns in early life are associated with diet in adolescence as reported by the mother and adolescent. Despite consistency of dietary behaviours between early childhood and adolescence, data in this study suggest that early growth is a more important determinant of adolescent BMI. Maternal nutritional education to optimize their child's diet has the potential to influence nutrition throughout childhood and adolescence; however, interventions focussing on minimizing early weight gain may have a greater impact on the obesity epidemic seen in our population. These findings extend our understanding of the complex interplay between behavioural, nutritional and sociodemographic contributors to obesity's early-life origins. The Raine cohort continues to be followed and thus provides unique opportunities to explore these relationships into adulthood.

\section{Acknowledgements}

The authors would like to acknowledge the Raine Study Team for their cohort co-ordination and data collection and the National Health and Medical Research Council (NH\&MRC) 
of Australia and Telethon Institute for Child Health Research for their long-term support and contribution to funding. Special thanks must go to the Raine Study participants and their families for their ongoing participation in the study.

\section{Sources of funding}

Funding for Core Management of the Raine Study has been provided by The University of Western Australia, The Telethon Institute for Child Health and Research, the Raine Medical Research Foundation, the University of Western Australia Faculty of Medicine, Dentistry and Health Sciences and the Women's and Infants' Research Foundation. Funding for the 1-3-, 5-, 8- and 10- year cohort reviews was provided by the NH\&MRC and the Raine Foundation. The 14-year-follow-up was funded by the NH\&MRC (Sly et al., ID 211912), NH\&MRC Program Grant (Stanley et al., ID 003209) and the Raine Foundation. Funding for the 17-yearfollow-up was provided by the NH\&MRC Program Grant (Stanley et al., ID 353514). Claire Meyerkort was funded by the King Edward Memorial Hospital Women's Health Research Scholarship.

\section{References}

1. WHO. Obesity: preventing and managing the global epidemic. Report of a WHO consultation. World Health Organ Tech Rep Ser. 2000; 894, i-xii.

2. WHO. Global health risks: mortality and burden of disease attributable to selected major risks. 2009; available from http://www.who.int/healthinfo/global_burden_disease/ global_health_risks/en/index.html

3. Hoad V, Somerford P, Katzenellenbogen J. High body mass index overtakes tobacco as the leading independent risk factor contributing to disease burden in Western Australia. Aust N Z J Public Health. 2010; 34, 214-215.

4. Jia H, Lubetkin E. Trends in quality-adjusted life-years lost contributed by smoking and obesity. Am J Prev Med. 2010; 38, 138-144.

5. Wang Y, Lobstein T. Worldwide trends in childhood overweight and obesity. Int J Pediatr Obes. 2006; 1, 11-25.

6. Oude Luttikhuis H, Baur L, Jansen H, et al. Interventions for treating obesity in children. Cochrane Databse of Systematic Reveiws. 2009; Issue 1, Art. no. CD001872.

7. Mikkilä V, Räsänen L, Raitakari $O$, Pietinen $P$, Viikari J. Consistent dietary patterns identified from childhood to adulthood: the cardiovascular risk in Young Finns Study. Br J Nutr. 2005; 93, 923-931.

8. Wang Y, Bentley ME, Zhai F, Popkin BM. Tracking of dietary intake patterns of Chinese from childhood to adolescence over a six-year follow-up period. J Nutr. 2002; 132, 430-438.

9. Kemper H, Post G, Twisk J, Van Mechelen W. Lifestyle and obesity in adolescence and young adulthood: results from the Amsterdam Growth And Health Longitudinal Study (AGAHLS). Int J Obes Relat Metab Disord. 1999; 23 (Suppl 3), S34-S40.

10. Northstone K, Emmett P. Are dietary patterns stable throughout early and mid-childhood? A birth cohort study. Br J Nutr. 2008; 100, 1069-1076.
11. Barker DJ, Winter PD, Osmond C, Margetts B, Simmonds SJ. Weight in infancy and death from ischaemic heart disease. Lancet. 1989; 2, 577-580.

12. Hales CN, Barker DJ, Clark PM, et al. Fetal and infant growth and impaired glucose tolerance at age 64. BMJ. 1991; 303, 1019-1022.

13. Newnham JP, Pennell CE, Lye SJ, Rampono J, Challis JR. Early life origins of obesity. Obstet Gynecol Clin North Am. 2009; 36, 227-244.

14. Hales CN, Barker DJ. Type 2 (non-insulin-dependent) diabetes mellitus: the thrifty phenotype hypothesis. Acta Diabetol. 1992; 35, 595-601.

15. Gluckman P, Cutfield W, Hofman P, Hanson M. The fetal, neonatal, and infant environments-the long-term consequences for disease risk. Early Hum Dev. 2005; 81, 51-59.

16. Baird J, Fisher D, Lucas P, et al. Being big or growing fast: systematic review of size and growth in infancy and later obesity. BMJ. 2005; 331, 929.

17. Monteiro P, Victora C. Rapid growth in infancy and childhood and obesity in later life-a systematic review. Obes Rev. 2005; 6, 143-154.

18. Horta B, Bahl R, Martines J, Victora C. Evidence on the long-term effects of breastfeeding, 2007; World Health Organization: Geneva.

19. Cope M, Allison D. Critical review of the World Health Organization's (WHO) 2007 report on'evidence of the longterm effects of breastfeeding: systematic reviews and metaanalysis' with respect to obesity. Obes Rev. 2008; 9, 594-605.

20. Scaglioni S, Agostoni C, Notaris RD, et al. Early macronutrient intake and overweight at five years of age. Int J Obes Relat Metab Disord. 2000; 24, 777-781.

21. Rolland-Cachera MF, Deheeger M, Akrout M, Bellisle F. Influence of macronutrients on adiposity development: a follow up study of nutrition and growth from 10 months to 8 years of age. Int J Obes Relat Metab Disord. 1995; 19, 573-578.

22. Hu F. Dietary pattern analysis: a new direction in nutritional epidemiology. Curr Opin Lipidol. 2002; 13, 3-9.

23. Cheng G, Gerlach S, Libuda L, et al. Diet quality in childhood is prospectively associated with the timing of puberty but not with body composition at puberty onset. J Nutr. 2010; 140, 95-102.

24. Feskanich D, Rockett HR, Colditz GA. Modifying the Healthy Eating Index to assess diet quality in children and adolescents. J Am Diet Assoc. 2004; 104, 1375-1383.

25. Hurley KM, Oberlander SE, Merry BC, et al. The healthy eating index and youth healthy eating index are unique, nonredundant measures of diet quality among low-income, African American adolescents. J Nutr. 2009; 139, 359-364.

26. Kranz S, Findeis JL, Shrestha SS. Use of the Revised Children's Diet Quality Index to assess preschooler's diet quality, its sociodemographic predictors, and its association with body weight status. J Pediatr (Rio J). 2008; 84, 26-34.

27. Evans S, Newnham J, MacDonald W, Hall C. Characterisation of the possible effect on birthweight following frequent prenatal ultrasound examinations. Early Hum Dev. 1996; 45, 203-214.

28. Newnham JP, Evans SF, Michael CA, Stanley FJ, Landau LI. Effects of frequent ultrasound during pregnancy: a randomised controlled trial. Lancet. 1993; 342, 887-891.

29. Williams LA, Evans SF, Newnham JP. Prospective cohort study of factors influencing the relative weights of the placenta and the newborn infant. BMJ. 1997; 314, 1864-1868. 
30. Li J, Kendall GE, Henderson S, et al. Maternal psychosocial well-being in pregnancy and breastfeeding duration. Acta Paediatr. 2008; 97, 221-225.

31. Binns C, Baghurst K. Dietary Guidelines for Children and Adolescents in Austraila, 2003. National Health and Medical Research Council, Canberra, Australia.

32. Baghurst K, Record S. A computerised dietary analysis system for use with diet diaries or food frequency questionnaires. Community Health Stud. 1984; 8, 11-18.

33. Nelson M, Bingham S. Assessment of food consumption and nutrient intake. Design concepts in nutritional epidemiology. 1997; 1, 123-170.

34. Ambrosini GL, Oddy WH, Robinson M, et al. Adolescent dietary patterns are associated with lifestyle and family psychosocial factors. Public Health Nutr. 2009; 12, 1807-1815.

35. Ambrosini GL, O’Sullivan T, De Klerk NH, et al. Relative validity of adolescent dietary patterns: a comparison of a FFQ and $3 \mathrm{~d}$ food record. Br J Nutr. 2010; 105, 625-633.

36. Pink B. Australian Bureau of Statistics: Socio-Economic Indexes for Areas (SEIFA) - Technical Paper, Canberra. Report no.: ABS Catalogue no. 2039.0.55.001, 2006.

37. SPSS. SPSS for Windows, 2009; SPSS Inc.: Chicago.

38. Kramer M, Kakuma R. The optimal duration of exclusive breastfeeding: a systematic review. Adv Exp Med Biol. 2004; 554, 63-77.

39. Cooke L, Wardle J, Gibson E, et al. Demographic, familial and trait predictors of fruit and vegetable consumption by pre-school children. Public Health Nutr. 2004; 7, 295-302.

40. Noble S, Emmett P. Differences in weaning practice, food and nutrient intake between breast-and formula-fed 4-month-old infants in England. J Hum Nutr Diet. 2006; 19, 303-313.

41. Koletzko B, von Kries R, Closa R, et al. Can infant feeding choices modulate later obesity risk? Am J Clin Nutr. 2009; 89 (Suppl), 1502S-1508S.

42. Patterson E, Wärnberg J, Kearney J, Sjöström M. The tracking of dietary intakes of children and adolescents in Sweden over six years: the European Youth Heart Study. Int J Behav Nutr Phys Act. 2009; 6, 91.

43. Singer M, Moore L, Garrahie E, Ellison R. The tracking of nutrient intake in young children: the Framingham Children's Study. Am J Public Health. 1995; 85, 1673-1677.
44. Wolongevicz DM, Zhu L, Pencina MJ, et al. Diet quality and obesity in women: the Framingham Nutrition Studies. Br J Nutr. 2010; 103, 1223-1229.

45. Parsons T, Power C, Logan S, Summerbell C. Childhood predictors of adult obesity: a systematic review. Int J Obes Relat Metab Disord. 1999; 23 (Suppl 8), S1-S107.

46. Burke V, Beilin L, Simmer K, et al. Predictors of body mass index and associations with cardiovascular risk factors in Australian children: a prospective cohort study. Int J Obes. 2004; 29, 15-23.

47. Ong KK, Loos RJF. Rapid infancy weight gain and subsequent obesity: systematic reviews and hopeful suggestions. Acta Paediatr. 2006; 95, 904-908.

48. Huang R, Burke V, Newnham J, et al. Perinatal and childhood origins of cardiovascular disease. Int J Obes. 2006; 31, 236-244.

49. Oddy WH, Sherriff JL, de Klerk NH, et al. The relation of breastfeeding and body mass index to asthma and atopy in children: a prospective cohort study to age 6 years. Am J Public Health. 2004; 94, 1531-1537.

50. Burke V, Beilin LJ, Simmer K, et al. Breastfeeding and overweight: longitudinal analysis in an Australian birth cohort. J Pediatr. 2005; 147, 56-61.

51. Huybrechts I, Vereecken C, De Bacquer D, et al. Reproducibility and validity of a diet quality index for children assessed using a FFQ. Br J Nutr. 2010; 104, 135-144.

52. Kleiser C, Mensink GB, Scheidt-Nave C, Kurth BM. HuSKY: a healthy nutrition score based on food intake of children and adolescents in Germany. Br J Nutr. 2009; 102, 610-618.

53. Kranz S, Hartman T, Siega-Riz A, Herring A. A diet quality index for American preschoolers based on current dietary intake recommendations and an indicator of energy balance. J Am Diet Assoc. 2006; 106, 1594-1604.

54. Australian Institute of Health and Welfare. Australia's Health, Canberra, 2008; available from www.aihw.gov.au/publicationdetail/?id=6442468102

55. Deierlein AL, Siega-Riz AM, Adair LS, Herring AH. Effects of pre-pregnancy body mass index and gestational weight gain on infant anthropometric outcomes. J Pediatr. 2011; 158, 221-226. 